\title{
Local versus national: designing supply systems for individual net zero energy buildings with flexible electricity prices
}

\author{
C. Milan, M. P. Nielsen \& C. Bojesen \\ Department of Energy Technology, Aalborg University, Denmark
}

\begin{abstract}
The building sector has obtained increased awareness throughout the last decades due to its notable contribution to global greenhouse gas (GHG) emissions. One approach to decrease these emissions is the concept of net zero energy buildings (Net ZEB), which produce as much energy out of renewable sources as they consume through public grid connections on an annual balance. A global design solution for these buildings does not exist, since the energy resource availability is different everywhere. In earlier publications a methodology was presented which allows for the cost optimal design of individual energy supply systems based on on-site weather and building conditions, as well as considering the expected energy consumption profile. However, local planning processes are problematic if they do not take regional or national impacts into account. Given the grid connection, the local building solution also has an impact on a national scale by exchanging electricity. Therefore it is important to implement respective grid loads into the planning process in order to avoid technology choices, which might counteract grid stability or cost inefficiencies at other sites. The aim of this paper is to adapt the earlier proposed methodology by integrating flexible national electricity prices and thus taking account for the aforementioned effects. The methodology is applied in a case study for a single family house under Danish conditions. The results show that the system configuration might not necessarily be changed but an adaptation in the mode of operation is important and could even lead to cost reductions when allowing for flexible tariffs.
\end{abstract}

Keywords: net zero energy buildings, zero energy buildings, cost optimization, renewable energies, supply system design, MILP, linear programming. 


\section{Introduction}

Currently, a transition is taking place in the building sector from fossil fuel consumption towards renewable energy producing houses. An important part of this process was the introduction of the Net ZEB concept, which set the basic requirement to deliver as much corresponding primary energy to the public grid as the building consumes on an annual scale [1]. Several characteristics of this new building definition necessitate innovative solutions for supply system design and configuration. Different supply options and design methodologies have been investigated in recent years for low energy and Net ZEBs [2-5]. The methodology presented in [6] and [7] proposed one approach for an individual and cost optimized supply system design in Net ZEBs. However, this approach does not yet take national planning or grid conditions into account. The obtained building specific solutions can cause cost and technical inefficiencies on a national scale. In this article, the proposed methodology will be extended towards supply systems, which are also considering regional or national interaction by applying flexible electricity prices and supporting grid stability.

\section{Designing supply systems}

Designing the supply system is one of the major challenges in Net ZEB planning. Besides the significant reduction of the buildings energy demand by adaptations in the building construction, the supply system is the second important measure to reach an annual energy balance of zero. In the following subchapters the characteristics are described, which should be considered in the design process of Net ZEB supply systems and a methodology is proposed to identify optimized installed capacities of relevant technologies in terms of overall system costs.

\subsection{The challenges}

Net zero energy buildings require certain considerations when designing the corresponding supply system. The five most important challenges are depicted in Figure 1.

The concept of Net ZEBs requires that the annual energy balance have to be zero. Therefore, technology capacities have to be chosen in a way that the annual energy demand will be covered. However, it has to be noted that Net ZEBs are should not be considered as island systems. Interaction with the public electricity grid and, if relevant, district heating networks is an important feature and can serve energy storage purposes. Furthermore, in opposite to standard supply solutions, Net ZEB systems in most of the cases rely on more than one energy source. These sources are additionally, apart from Hydrogen or Biomass fuels, fluctuating and not controllable, such as irradiation or wind. Another important characteristic is the cost structure of $100 \%$ renewable supply systems. The initial investment costs are substantially higher than for standard solutions and account 
for the major part of the overall net present system costs. On the contrary, annual operation costs are often negligible.

In summary it can be concluded that the aforementioned circumstances eliminate the possibility of applying conventional supply system design. For each Net ZEB an individual solution has to be elaborated based on the sitespecific conditions and aiming at the most cost effective configuration.

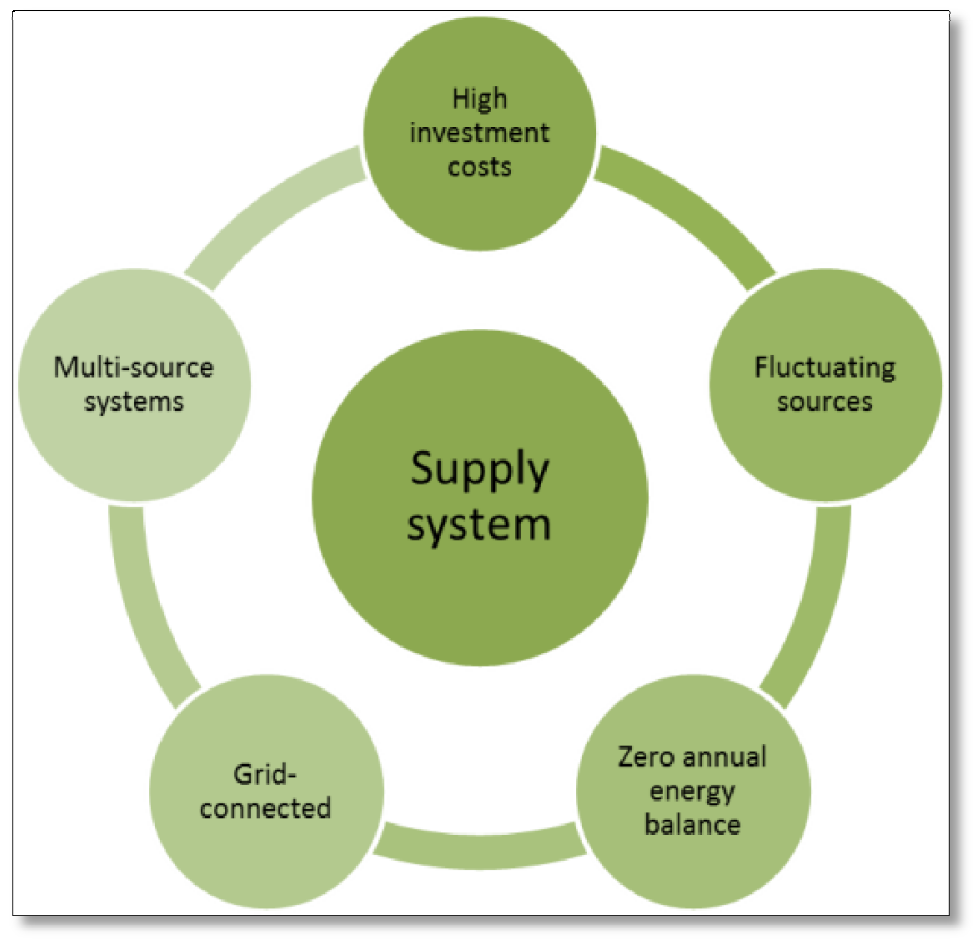

Figure 1: $\quad$ Challenges in supply system design for Net ZEBs.

\subsection{A uniform design methodology}

This paper is based on work presented in earlier publications as in Milan et al. $[6,7]$, where the following optimization methodology and underlying theory is described in detail. The three basic steps of the model are described as depicted in Figure 2.

The strength of the methodology lies in the fact that it accounts for weather conditions at the building site and expected consumption profiles with an hourly resolution for a reference year, which has to be specified in the first step. Further, all the technical specifications of the relevant technologies, such as market prices or performance models have to be adapted or updated to the investigated case before the optimization algorithm is started. The problem is formulated as a Mixed Integer Linear Problem and is currently programmed and solved with the 
software package GAMS [8]. After the algorithm has identified the optimal configuration and installed capacities of the supply system, also economic data, such as the net present system costs, and hourly-based production profiles for all relevant technologies are available for the reference year as this data is obtained as part of the calculation process.

The aim of this paper is to extend the presented methodology by implementing flexible electricity prices and therefore considering regional or national grid conditions.

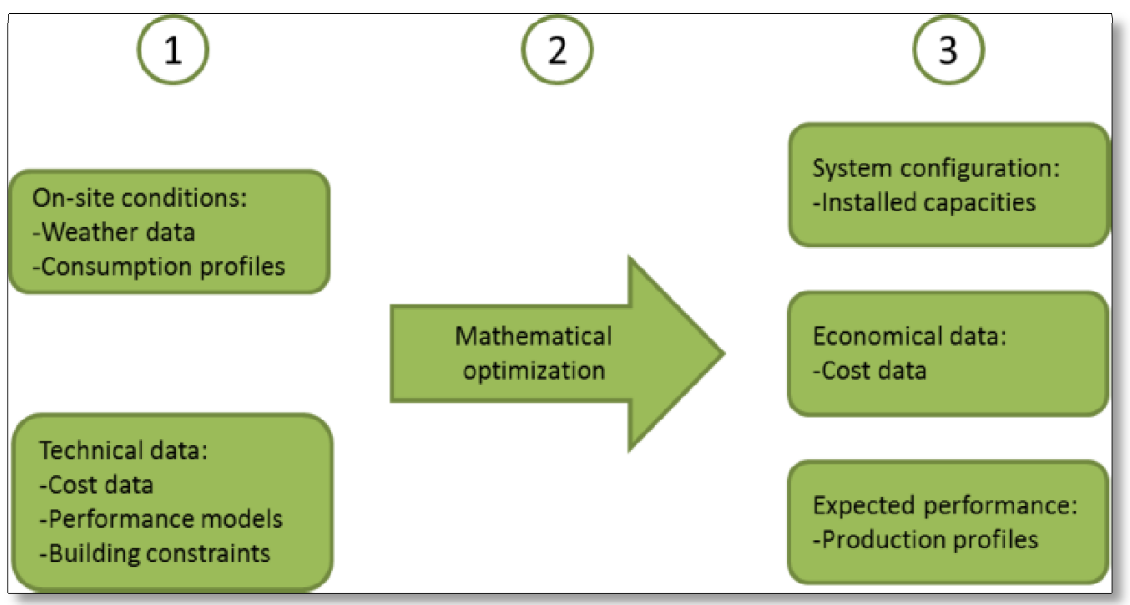

Figure 2: $\quad$ Sequence of the proposed methodology.

\subsection{Local vs. national design}

When designing local supply system solutions, the concerned building owners are often interested in the most cost effective solution from their perspective. Currently, small scale electricity consumers and producers are just paying or receiving a fixed price and therefore they are not interested in adapting their consumption or production profiles or even choice of technologies to the given conditions in the public grid. This is the reason why local cost-optimal solutions can lead to regional or national inefficiencies, if certain technologies or operation modes are applied by a large number of houses [9].

The methodology presented in the previous chapter determines the optimal configuration isolated from the public grid and is adapted in the following to assure that the optimal supply system on building level also complies with the national optimum. For this purpose flexible tariffs are used for electricity production and consumption. For simplicity reasons it is assumed that the price is the same for consuming electricity from the grid and for selling it back to the grid. The flexible tariffs are calculated by using an annual average price $\mathrm{P}_{\text {el,average }}$ multiplied with a price index $\mathrm{I}_{\mathrm{h}}$ for each hour.

$$
P_{\text {el,h }}=P_{\text {el,average }} * I_{h}
$$


The price index in this paper is based on hourly spot market prices, which are used to represent the electricity market conditions at each hour of the reference year. The price index is calculated by dividing the spot market price of each hour $\mathrm{P}_{\mathrm{el} \_ \text {spot, h }}$ by the average spot market price over the year. In this way the deviation from standard grid conditions can be quantified.

$$
I_{h}=\frac{P_{\text {el_spot }, h}}{\frac{\Sigma_{1}^{860} P_{\text {el_spot }, h}}{8760}}
$$

For determining the average spot market price, the arithmetic mean value is applied summing all hourly prices up and dividing them by 8760 , which corresponds to the number of hours per year. If other time resolutions are used, eqn (2) has to be adapted correspondingly.

\section{Investigating a Danish case}

The presented methodology has been successfully applied for a Danish reference case. In the following the major assumptions and input data for the calculations are discussed. In a second part the results of the simulations are presented and evaluated in detail.

\subsection{The Danish electricity market}

The Danish energy system is characterized by a large share of renewable energy resources. By far the largest contribution is generated by a multitude of wind parks [9]. This is the reason why Denmark is in relation to its electricity consumption the largest producer of electricity from wind turbines covering 28 percent of the national consumption [9]. Therefore, the Danish power system operators are facing extra challenges integrating a large share of fluctuating power sources into the public grid. Currently, as described earlier in this paper, Danish small scale consumers of electricity only receive a fixed price for consumed or on-site generated electricity, which is delivered to the grid [10]. In this paper it is investigated, which impact fluctuating electricity prices for small scale consumers would have on the optimal configuration of the building supply system in regard to Net ZEBs.

Corresponding to eqn (2) a price index was calculated for the Danish electricity market based on spot market prices of 2012. The prices are hourly based and where obtained from the Danish transmission system operator Energinet.dk [11]. Due to the geographical division of the country into several islands the Danish high voltage power system was long time separated into two separated units. Nowadays it is connected via a high voltage cable but still different electricity prices are valid for both regions [11]. Therefore, in the following a distinction is made between prices in West Denmark and East Denmark. In Table 1 the average spot market price for both regions in 2012 is shown and it can be stated that the price in Western Denmark is slightly lower than in the Eastern part of the country. 
768 Energy Production and Management in the 21st Century, Vol. 2

Table 1: Average spot market price in Denmark in 2012.

\begin{tabular}{|c|c|c|}
\hline Control Area & East Denmark & West Denmark \\
\hline $\begin{array}{c}\text { Average Spot } \\
\text { Market Price [€/Mwh] }\end{array}$ & 37.55 & 36.31 \\
\hline
\end{tabular}

In Figure 3 the calculated price index is shown for the year 2012 indicating the deviation from the price of each hour from the average price in Table 1. A price index of 1 corresponds to the average value.

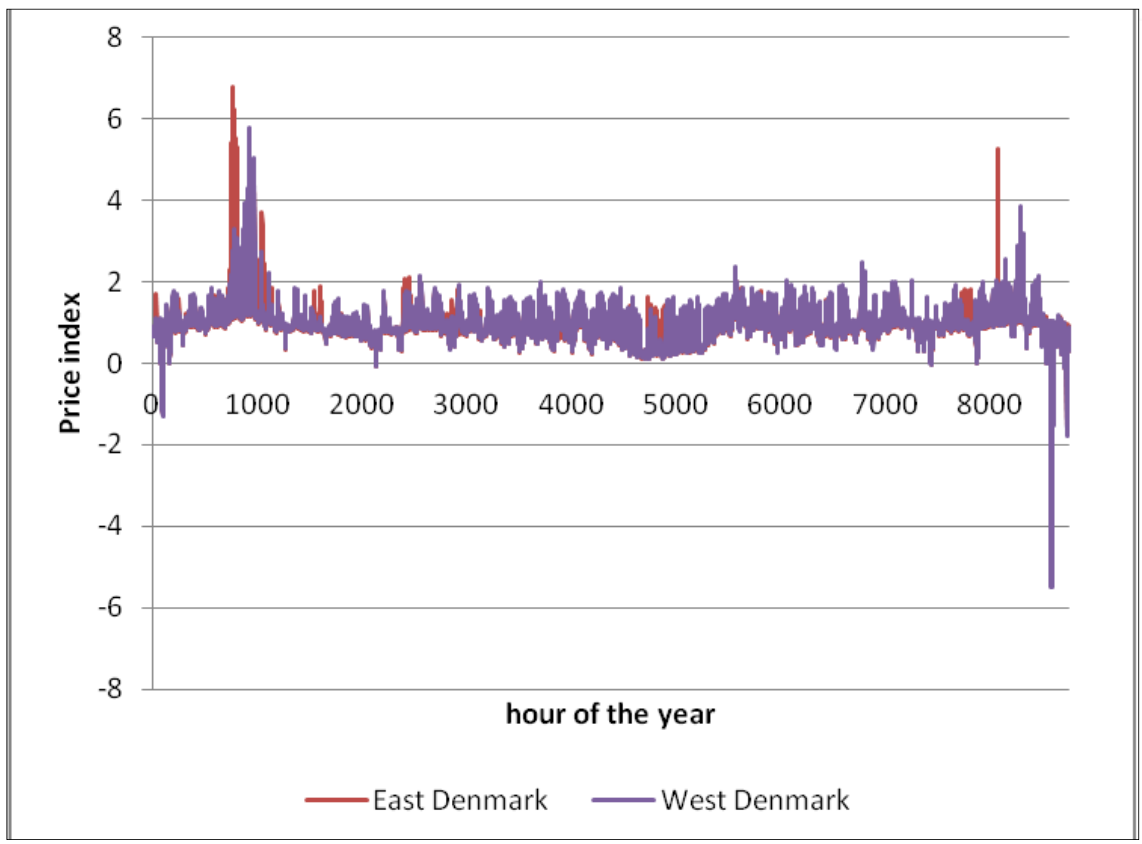

Figure 3: $\quad$ Price index based on the hourly deviation of spot market prices in Denmark in 2012.

According to the figure the largest deviations occur during winter time and even reaching large negative prices in rare cases. This is due to the large share of wind turbines and Combined Heat and Power plants (CHP) powering district heating networks. This leads in few cases throughout the year to prices close to zero or even to negative values, when it is not economical to shut down large base load power plants for very short periods.

In general it can be stated that for the western part of Denmark the fluctuations are more frequent and also slightly more extreme. The reason for this circumstance is the fact that the majority of wind turbines are installed in West Denmark [9]. 


\subsection{The reference case}

A Danish single family house with a two person household is assumed for the following case study. The house is supposed to be a low energy building with a south facing roof of $85 \mathrm{~m}^{2}$. The operational life span of the supply system is assessed to be 20 years. For the calculation of the net zero energy balance the Danish primary factor for grid electricity of 2.5 is used [12]. A security margin of $10 \%$ is included in the calculations of the optimal installed capacities to account for deviations in weather conditions and building consumption. The weather data is represented by the Danish reference year, providing typical hourly values for irradiation and ambient temperature based on long term observations of the Danish Meteorological Institute [13].

Table 2 summarizes the supply options implemented in the methodology specifying the assumed technology type and efficiency. The water storage tank is implemented with a fixed size of 200 liter and is not subject to the optimization, as it is a mandatory part of the system. Since the investigated building is a low energy house it is for the sake of simplicity assumed that the domestic hot water and the space heating circuit have the same input temperature of $55^{\circ} \mathrm{C}$ and are supplied from the same storage tank.

For electricity and fuels, in this case biogas for the CHP, an annual price increase is included in the calculations, as listed in Table 3. The price development for electricity is based on official estimations of the Danish Energy Agency [14]. For biogas an annual price increase of 3\% is assumed.

Table 2: Considered supply technologies in the case study.

\begin{tabular}{|c|c|c|}
\hline Technology & Type & Efficiency \\
\hline Photovoltaic & Polycrystalline & 0.12 \\
\hline Solar Thermal Collector & Glazed flat-plate & 0.79 (average) \\
\hline Heat pump & $\begin{array}{c}\text { Water based ground } \\
\text { source }\end{array}$ & 3.9 (average COP) \\
\hline Heat tank (200 liter) & $\begin{array}{c}\text { Short-term water tank } \\
\text { CHP }\end{array}$ & $\begin{array}{c}0.5 \% / \text { day (heat } \\
\text { losses) }\end{array}$ \\
\hline Reciprocating engine & $\begin{array}{c}0.63 \text { (thermal) } \\
0.26 \text { (electrical) }\end{array}$ \\
\hline
\end{tabular}

Table 3: Future electricity and fuel prices for Danish households.

\begin{tabular}{|c|c|c|}
\hline Year & Electricity $[€ / \mathrm{kWh}]$ & Biogas $\left[€ / \mathrm{m}^{3}\right]$ \\
\hline 2012 & 0.301 & 0.630 \\
\hline 2015 & 0.302 & 0.688 \\
\hline 2020 & 0.305 & 0.798 \\
\hline 2025 & 0.298 & 0.925 \\
\hline 2030 & 0.317 & 1.073 \\
\hline 2035 & 0.33 & 1.243 \\
\hline
\end{tabular}




\subsection{Results: local contradicts national?}

The cost optimal supply system configuration has been determined for the reference building applying the optimization methodology. As stated earlier, two different price levels for eastern (DK-East) and western (DK-West) Denmark have been used and compared to the results based on a fixed electricity price. The costs of the optimal sized supply system for all three cases are listed in Table 4.

The total system costs discounted to present value are based on the initial investment costs, the annual operation and maintenance expenses and decommissioning costs. In the table, over the whole life cycle averaged operational costs are given, since they differ for each year due to the discounting and changing fuel and electricity prices. In general, from the listed results it can be stated, that the investment costs have by far the major share of the total net present costs. In contrast to conventional systems the annual expenses for fuel and grid electricity are very low and are for the case with fixed electricity prices around 155 Euros. Further, the investment costs change only slightly if electricity prices are changed into flexible tariffs. However, the operational costs can be decreased significantly when assuming spot market based tariffs very close to zero. This is can be explained by, that electricity is mostly used in low load times, and delivered to the grid when electricity prices are highest. However, the price difference for the overall system costs is still rather low and accounts for ca. 120 Euros per year or 2,200 Euros over the system life time.

The fact that investment costs do not change, implies that the optimal configuration of the system does not differ either. This conclusion can be confirmed when investigating the determined capacities for each case, as depicted in Figure 4.

The optimal configuration for the supply system achieving a net zero energy balance for the reference building using fixed electricity prices consists of a large PV unit of around $9 \mathrm{~kW}$, a small ground source heat pump of around $2 \mathrm{~kW}$ and a micro CHP of $0.1 \mathrm{~kW}$. The PV module is by far the largest, since it is the only technology available producing independently electricity. The electricity produced by the solar cells has to cover the electricity demand of the building and of the heat pump. Further, it has to balance out primary energy embodied in the supply technologies as well as grid consumed electricity by delivering the corresponding amount back to the grid.

Table 4: System costs for the optimal supply system.

\begin{tabular}{|c|c|c|c|}
\hline El-Price & $\begin{array}{c}\text { Net present } \\
\text { costs [€] }\end{array}$ & $\begin{array}{c}\text { Investment } \\
\text { costs [€] }\end{array}$ & $\begin{array}{c}\text { Average operation } \\
\text { costs [€/year] }\end{array}$ \\
\hline Annual Fixed & 44,400 & 36,500 & 155 \\
\hline Flexible DK-East & 41,800 & 36,700 & 13 \\
\hline Flexible DK-West & 42,000 & 36,800 & 21 \\
\hline
\end{tabular}




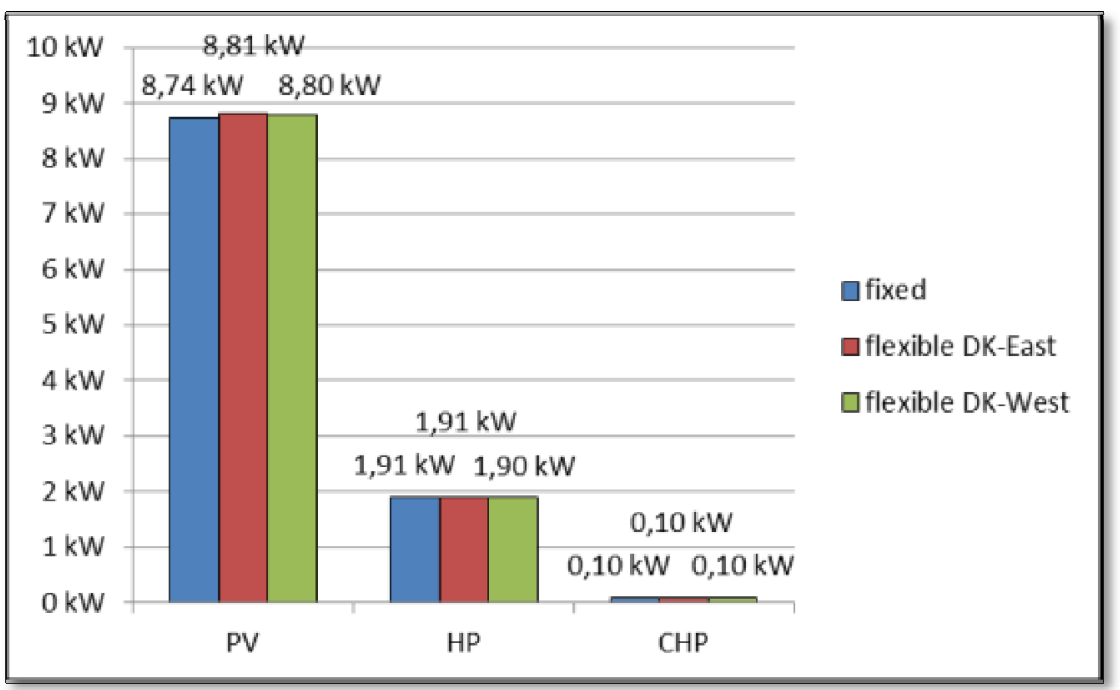

Figure 4: $\quad$ Optimal capacities of the supply system for the case study.

As stated earlier, this configuration does differ only slightly, when using the on-site supply system for grid support by applying flexible tariffs. Since only the annual operation costs change, it can be concluded that the load management is adapted. This becomes obvious when comparing the heat production curves for the standard case with fixed prices in Figure 5 and for the case with flexible electricity prices in eastern Denmark as depicted in Figure 6. In both cases the heat production is directly coupled to the electricity consumption profile, since the power input for the heat pump is electricity and since the CHP produces electricity and heat simultaneously.

In Figure 5 the heat pump produces almost constantly heat throughout the year adapted to the respective heat demand in each hour. The CHP is supplying constant base load in winter, autumn and spring time and is switched off during summer time. This picture totally changes when flexible tariffs apply. The heat pump is operated throughout the year with the maximum power and in an on-offmode. When prices are low, the heat pump fills up the water tank and switches off during high load times. The maximal power output in summer is higher due to the increase in ground temperature and therefore the COP. It should be noted that in winter times the heat pump is neither operated constantly, but switched off during several hours. This is simply not visible in the figure due to the resolution. The CHP operation mode has changed from a seasonal to an all-year application. In contrary to the heat pump the CHP is producing heat during high tariff times, since electricity and heat are generated simultaneously. In this way both technologies are complement to each other and assure a constant supply of heat in combination with the heat tank. 


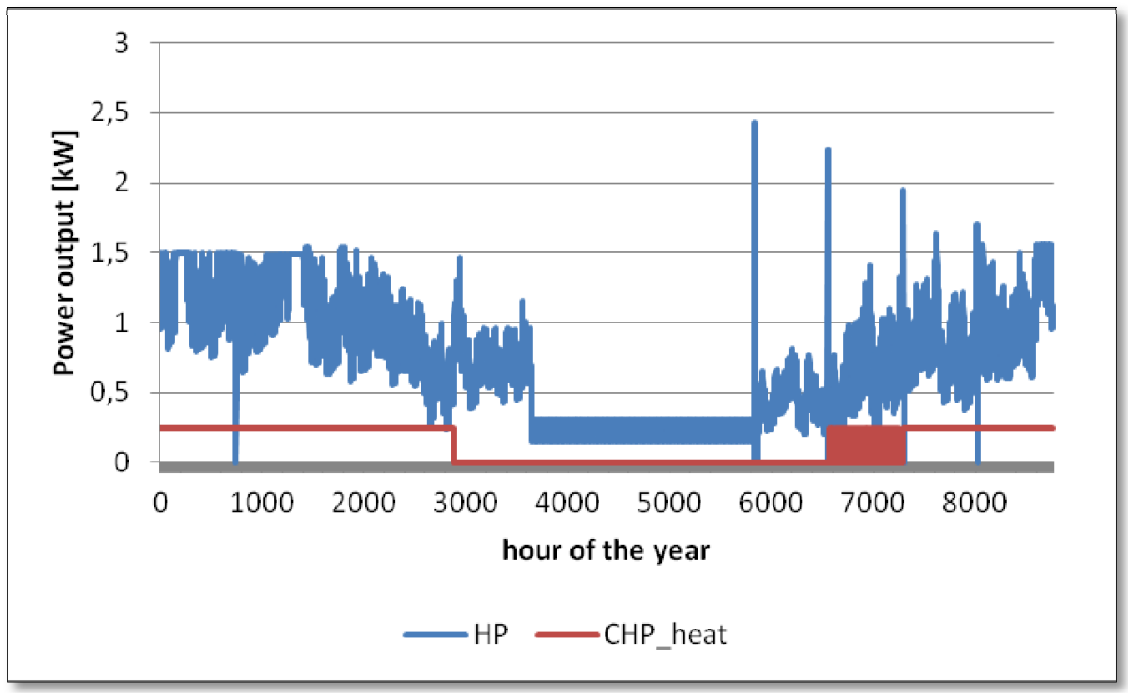

Figure 5: Heat production of the supply system with fixed electricity prices.

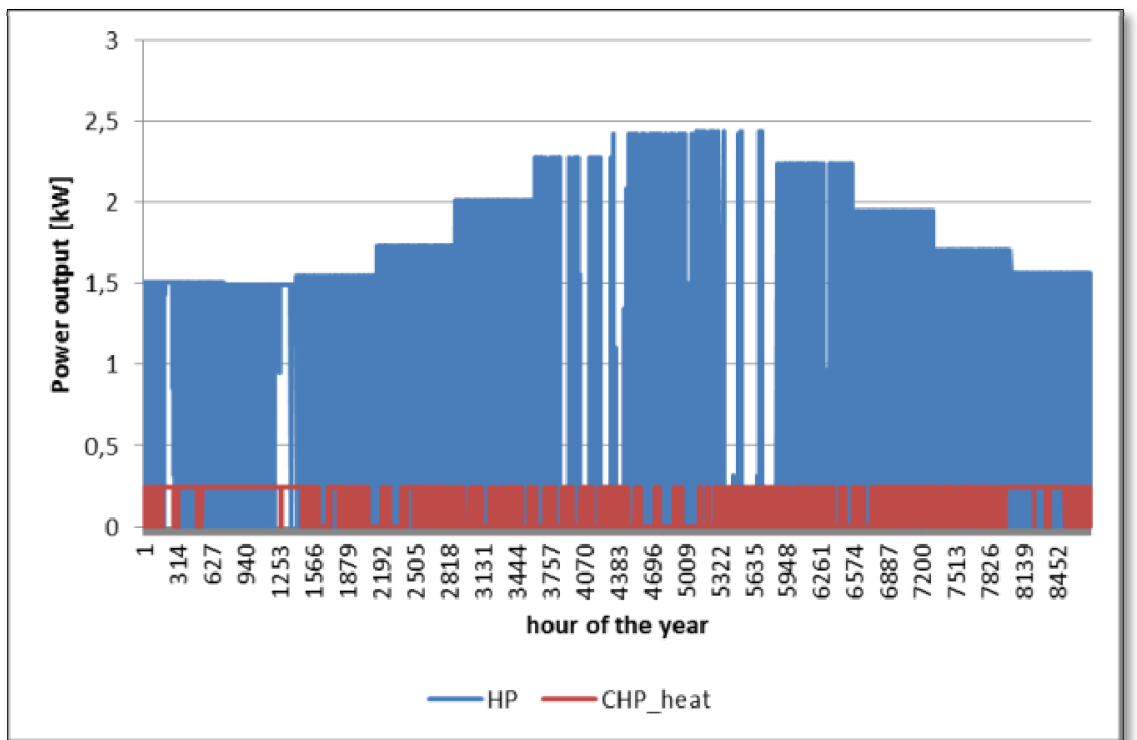

Figure 6: Heat production of the supply system with variable electricity prices (East Denmark). 


\section{Conclusion}

The presented optimization methodology has been adapted to take into account regional or national interests in the supply system design process on a building level. Based on the modifications a case study for a single family house under Danish conditions it could be shown that system configuration does not implicitly change when requiring grid support from the supply system. Moreover, the mode of operation of the supply technologies would change and electricity as well as heat production is regulated according to the respective state of the grid. It further could be shown that due to the adapted performance even cost reductions between 86 and $92 \%$ could be realized in annual electricity expenses for the reference case. Concluding, it has be mentioned that the determined capacities should be seen more as a theoretical indication of the optimal configuration, since a micro-CHP with an electrical output of $0.1 \mathrm{~kW}$ is not yet available on the market. Investigations with discrete market available capacities will be part of future publications.

\section{References}

[1] Marszal, A. J., Heiselberg, P., Bourrelle, J. S., Musall, E., Voss, K., Sartori, I. \& Napolitano, A., Zero Energy Building - A Review of definitions and calculation methodologies, Energy Build., 43(4), pp. 971-979, 2011.

[2] Wang, L., Gwilliam, J. \& Jones, P., Case study of zero energy house design in UK, Energy Build., 41(11), pp. 1215-1222, Nov. 2009.

[3] Charron, R. \& Athienitis, A., Design and Optimization of Net Zero Energy Solar Homes, Trans.-Am. Soc. Heat. Refrig. Air Cond. Eng., $112(2)$, p. 285, 2006.

[4] Kolokotsa, D., Rovas, D., Kosmatopoulos, E. \& Kalaitzakis, K., A roadmap towards intelligent net zero- and positive-energy buildings, Sol. Energy, 85(12), pp. 3067-3084, 2011.

[5] Marszal, A. J., Heiselberg, P., Jensen, R. L. \& Nørgaard, J., On-site or off-site renewable energy supply options? Life cycle cost analysis of a Net Zero Energy Building in Denmark, Renew. Energy, 44, pp. 154-165, Aug. 2012.

[6] Milan, C., Bojesen, C. \& Nielsen, M.P., A cost optimization model for $100 \%$ renewable residential energy supply systems, Energy, 48(1), pp. 118-127, 2012.

[7] Milan, C., Bojesen, C. \& Nielsen, M.P., Choosing The Right Technology - Optimized Design Of Renewable Supply Systems For Residential Houses, in Proceedings of the 11th International Conference on Sustainable Energy Technologies 2012, Vancouver, Canada, 2012.

[8] GAMS Development Corporation, “GAMS - A User's Guide.” GAMS Development Corporation, 2010.

[9] Danish Energy Agency, Energy Statistics 2011, 2011.

[10] Energinet.dk, www.energinet.dk. 
774 Energy Production and Management in the 21st Century, Vol. 2

[11] Energinet.dk, Download of market data, 2013. [Online]. Available: http://www.energinet.dk/EN/El/Engrosmarked/Udtraek-af-markedsdata /Sider/default.aspx. [Accessed: 02-May-2013].

[12] Voss, K. \& Musall, E., Net Zero Energy Buildings: International comparison of carbon-neutral lifestyles, 1. Edition, Birkhäuser Architektur, 2012.

[13] Jensen, J. M. \& Lund, H., Design reference year, DRY: et nyt dansk reference år. Technical University of Denmark, Laboratory for Heat Isolation, 1995 [in Danish].

[14] Danish Energy Agency, "Udviklingen i de fremtidige energipriser, herunder sikkerhed i tallene." 2012 [in Danish]. 